\title{
The Physical Properties of Erbium-Doped Yttrium Iron Garnet Films Prepared by Sol-Gel Method
}

\author{
Ramadan Shaiboub, Noor Baa'yah Ibrahim, Mustafa Abdullah, and Ftema Abdulhade \\ School of Applied Physics, Faculty of Science and Technology, The National University of Malaysia, Selangor, 43600 Bangi, Malaysia \\ Correspondence should be addressed to Noor Baa’yah Ibrahim, baayah@ukm.my
}

Received 23 January 2011; Revised 27 February 2011; Accepted 4 April 2011

Academic Editor: Parvaneh Sangpour

Copyright ( $) 2012$ Ramadan Shaiboub et al. This is an open access article distributed under the Creative Commons Attribution License, which permits unrestricted use, distribution, and reproduction in any medium, provided the original work is properly cited.

$\mathrm{Er}_{x} \mathrm{Y}_{3-x} \mathrm{Fe}_{5} \mathrm{O}_{12}$ nanoparticle films $(x=0.0,0.6,1.2,2.0$, and 2.5) have been synthesized by a sol-gel technique. All of the samples were annealed at $1000^{\circ} \mathrm{C}$. The nanostructures were characterized by an X-ray diffractometer (XRD), the magnetic properties and the grain size were studied using a vibrating sample magnetometer (VSM), and a field emission scanning electron microscope (FE-SEM), respectively. The XRD patterns of the films show single phase structure. The sizes of the particles are in the range of 78 to $89 \mathrm{~nm}$. The VSM result shows that the saturation magnetization of $\mathrm{Er}_{x} \mathrm{Y}_{3-x} \mathrm{Fe}_{5} \mathrm{O}_{12}$ films decreased with the increment of Er concentration $(x)$.

\section{Introduction}

The rare-earth iron garnet (RIG) has the general unit formula $\left(\mathrm{R}_{3} \mathrm{Fe}_{5} \mathrm{O}_{12}\right)$, where $\mathrm{R}$ is either a trivalent rare-earth ion or yttrium. RIGs belong to the space group Ia3d. The magnetic ions are distributed over three crystallographic sites with sublattice magnetization $\mathrm{Ma}$ [octahedral site, $16 \mathrm{Fe}^{3+}$ ions in a], $M d$ (tetrahedral site, $24 \mathrm{Fe}^{3+}$ ions in d) and $M c$ dodecahedral site, $24 \mathrm{R}^{3+}$ ions in c. The garnets have eight formula units in a cubic unit cell. The cubic unit cells of RIGs have approximately the same lattice constant which is of the order of $12 \mathrm{~A}^{\circ}[1]$, due to similar ionic radii of $\mathrm{R}^{3+}$ ions. Ionic distribution in garnet is represented as $\left\{\mathrm{R}_{3}{ }^{3+}\right\}\left[\mathrm{Fe}_{2}{ }^{3+}\right]$ $\left(\mathrm{Fe}_{3}{ }^{3+}\right) \mathrm{O}_{12}{ }^{2-}$. The interaction between the $\mathrm{Fe}^{3+}$ ions in [a] and (d) sites is strongly antiferromagnetic due to strong superexchange interaction. The magnetic moment of the rare-earth ions in the $\{c\}$ sublattice couples antiparallel with the resultant moment of $\mathrm{Fe}^{3+}$ ions. One of the common RIGs is $\mathrm{YIG}\left(\mathrm{Y}_{3} \mathrm{Fe}_{5} \mathrm{O}_{12}\right)$ which have attracted much attention in telecommunications and data storage industries due to their interesting magnetic and magneto-optic properties [2]. The $\mathrm{Y}^{3+}$ in YIG has no magnetic moment, so the net magnetic moment in YIG is due to the unequal distribution of $\mathrm{Fe}^{3+}$ ions in the two different sublattices of [a] and (d). YIGs are also of scientific importance because of the wide variety of magnetic properties that can be obtained by substituting yttrium with a rare-earth (RE) metal [3-9]. Most of the previous studies have concentrated on the preparation of $\mathrm{Bi}$ - and Ce-doped YIG (powder and films) nanoparticles because of their high Faraday rotation coefficient [10-17]. Few works have been carried out to study only Er-YIG powder nanoparticles [18-27]. In this paper we studied magnetic properties of Er doped YIG films in the formula $\mathrm{Er}_{x} \mathrm{Y}_{3-x} \mathrm{Fe}_{5} \mathrm{O}_{12}$ prepared by sol-gel method. Erbium is chosen because its ionic radius is (1.03 $\AA$ ), which is slightly less than ionic radii of yttrium $(1.04 \AA \hat{)})[28,29]$, it has an extremely high verdet constant and largest Bohr magneton [30].

\section{Experimental}

The YIG precursor sol was prepared by a sol-gel method using reagent grade nitrates purchased from Aldrich, Milwaukee, WI, USA. Yttrium nitrate hexahydrate $\left[\mathrm{Y}_{(} \mathrm{NO}_{3}\right)_{3}$. $6 \mathrm{H}_{2} \mathrm{O}, 99.95 \%$ purity], iron(III) nitrate nanohydrate $\left[\mathrm{Fe}\left(\mathrm{NO}_{3}\right)_{3} \cdot 9 \mathrm{H}_{2} \mathrm{O}, 98+\%\right.$ purity], and Erbium nitrate pentahydrate $\left[\mathrm{Er}\left(\mathrm{NO}_{3}\right)_{3} \cdot 5 \mathrm{H}_{2} \mathrm{O}\right]$ have been used as the raw materials; 2-methoxyethanol and acetic acid were used as solvents. $\mathrm{Fe}\left(\mathrm{NO}_{3}\right)_{3} \cdot 9 \mathrm{H}_{2} \mathrm{O}$ and $\mathrm{Y}\left(\mathrm{NO}_{3}\right)_{3} \cdot 6 \mathrm{H}_{2} \mathrm{O}$ were dissolved in the 2-methaxythanol and refluxed at $80^{\circ} \mathrm{C}$ for 3 hours. 


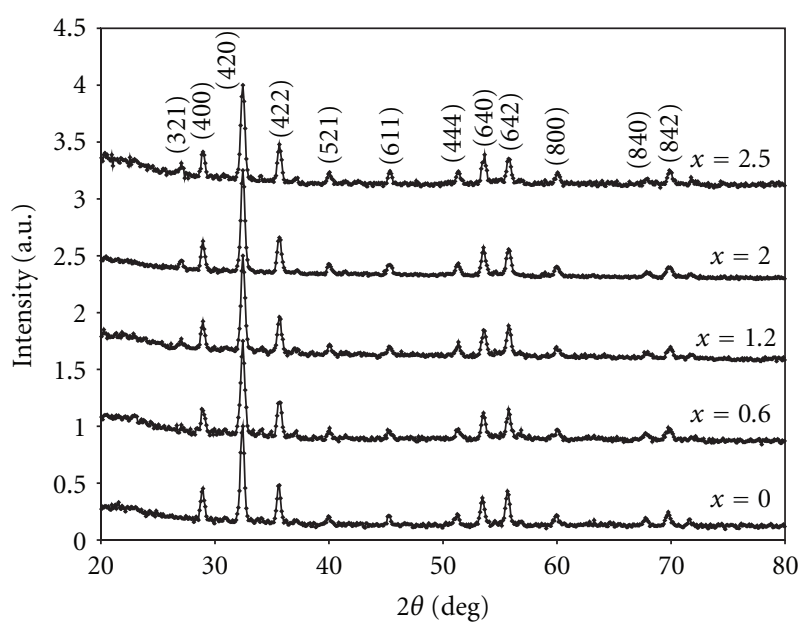

FIgURE 1: XRD patterns for $\mathrm{Er}_{x} \mathrm{Y}_{3-x} \mathrm{Fe}_{5} \mathrm{O}_{12}$ thin films.

The $\mathrm{Er}\left(\mathrm{NO}_{3}\right)_{3} \cdot 5 \mathrm{H}_{2} \mathrm{O}$ dissolved in acetic acid was added gradually into the $\mathrm{Fe}-\mathrm{Y}$ solution. Then the refluxing process was continued for 3 hours. Then a small quantity of diethylamine was added to the mixture solution while the $\mathrm{pH}$ value was adjusted in the range of 2-3. After cooling down to room temperature, the solution was stirred for 3 days.

The gel was transformed into a film on a quartz substrate using the spin coating technique. The rate of the spinning process was $3500 \mathrm{rpm}$ and it was done for 30 seconds. After the spinning process, the film was heated at $90^{\circ} \mathrm{C}$ for 2 hours to remove residual solvents. Then the heat treatment was carried out: initial heating at $350^{\circ} \mathrm{C}$ for 15 minutes at a heating rate of $3^{\circ} \mathrm{C} / \mathrm{min}$ to burn-off the organic materials followed by heating at $1000^{\circ} \mathrm{C}$ for 2 hours at a heating rate of $4^{\circ} \mathrm{C} / \mathrm{min}$ to crystalline the films. The characterizations were carried out using X-ray diffractometer (XRD), vibrating sample magnetometer (VSM), and field emission scanning electron microscope (FE-SEM).

\section{Results and Discussion}

3.1. X-Ray Diffraction Measurements. Figure 1 shows the XRD spectra for $\mathrm{Er}_{x} \mathrm{Y}_{3-x} \mathrm{Fe}_{5} \mathrm{O}_{12}$ thin films, $(0 \leq x \leq 2.5)$ annealed at $1000^{\circ} \mathrm{C}$ for 2 hours. All of the samples show single phases with diffraction lines (hkl) corresponding to the cubic garnet structure. The family of planes (hkl) in the Er-YIG structure and the corresponding distance between two lattice planes $d_{h k l}$ calculated from the experimental data are shown in Table 1. The theory data is according to the reference spectrum of a pure cubic garnet single phase formation YIG (JCPDS card no: 01-070-0953). The main peaks for $x=1.2,2.0$ and $x=2.5$ belonging to (321) reflection plane originated at the $2 \theta^{\circ}$ values of 27.014 , 27.022 , and 27.031 correspond to the spacing values of 3.298 , 3.297, and 3.296 $\AA$, respectively, which is one of the cubic garnet single phase formation according to the reference spectrum of (EIG) card no: 01-081-0131.

The lattice parameter "a" was calculated from combination of Bragg's equation and d-spacing expression for cubic system using the formula:

$$
a=\left[\frac{\lambda^{2}}{4 \sin ^{2} \theta}\left(h^{2}+k^{2}+l^{2}\right)\right]^{1 / 2},
$$

where $\lambda$ is the wavelength of $\mathrm{Cu} k \alpha$ radiation with $1.54060 \AA$, $\theta=$ diffraction angle of X-rays.

The average crystallite size was calculated according to the Scherrer's equation,

$$
D=\frac{k \lambda}{\beta \cos \theta},
$$

where $D$ is the mean crystallite size, $k(0.89)$ is the Scherrer constant, $\lambda$ is X-ray wavelength $(0.154252 \mathrm{~nm})$, and $\beta$ is the relative value of the full width at half maximum (FWHM) of the diffraction peak (420). Table 2 summarizes the results of lattice constant and crystallite size of $\mathrm{Er}_{x} \mathrm{Y}_{3-x} \mathrm{Fe}_{5} \mathrm{O}_{12}$ thin films.

3.2. Nanostructural Properties. The purpose of FESEM analysis was to determine the grain size and to understand the process of grain growth. The nanostructures of all of the samples were studied using the field emission scanning electron microscope (FE-SEM) at the magnification of $300,000 X$ (Figure 2). Most of the particles stuck to each other and form agglomerates due to their high surface energy [31]. The FESEM micrograph exhibited highly agglomerated particles having an average particle size of $82 \mathrm{~nm}$. It was observed that the average particle size measured by FESEM is bigger than crystallite size measured by Scherer's formula. This means that the particles are not single crystals and may consist of 2 or 3 and more crystallites.

The samples were coated with thin layer of gold to avoid electrostatic charging during examination. The grains could not be seen clearly. This may be because of masking caused by the gold coating on the film's surface. The average grain size is estimated from the FESEM and from the sample's cross section for $(x=0)$. The small grains on the surface belong to the gold particles $(10-20 \mathrm{~nm})$. The formation of cracks and voids can be attributed to the lattice mismatch. Cracks can easily be generated in crystallized Er-YIG thin films. The FESEM was also used to measure the films thicknesses and the result was $380 \mathrm{~nm}$. It should be noted that all preparation parameters that influence the film thickness such as the sol concentration, spinning rate, spinning duration, and amount of sol on the substrate were kept constant. The changing factor was only the $x$ value in this study.

3.3. Magnetic Properties. The magnetic properties of the films were measured using the vibrating samples magnetometer (VSM) with a maximum applied field of $12 \mathrm{kOe}$ at room temperature $\left(25^{\circ} \mathrm{C}\right)$. Figure 3 shows the in-plane hysteresis loop for all of the films. The hysteresis curves indicate that the Er-YIG films annealed at $1000^{\circ} \mathrm{C}$ are soft magnetic materials.

The saturation magnetization $\left(M_{s}\right)$ of the films decreased in a linear manner with the increment of Er concentration (x) (Figure 4(a)), and this can be related to the fact that 
TABLE 1: The experimental data for Er-YIG structure.

\begin{tabular}{|c|c|c|c|c|c|c|c|c|c|c|c|c|}
\hline (hkl) & $(321)$ & $(400)$ & $(420)$ & $(422)$ & $(521)$ & $(611)$ & $(444)$ & $(640)$ & $(642)$ & $(800)$ & $(840)$ & $(842)$ \\
\hline $\mathrm{d}_{\mathrm{hkl}}( \pm 0.005) \AA$ & 3.308 & 3.088 & 2.763 & 2.522 & 2.256 & 2.004 & 1.783 & 1.714 & 1.651 & 1.543 & 1.382 & 1.348 \\
\hline
\end{tabular}
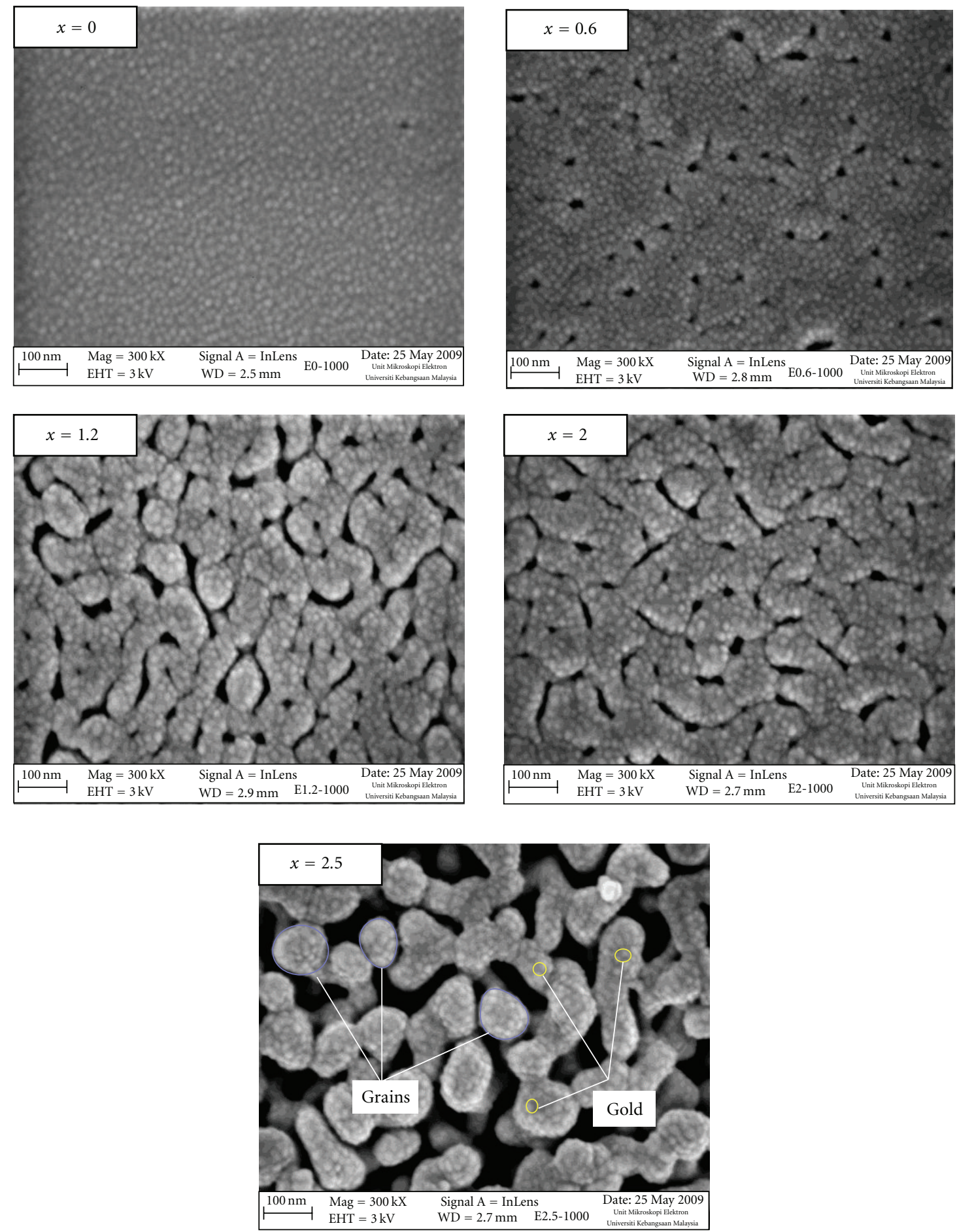

Figure 2: FE-SEM micrographs of $\mathrm{Er}_{x} \mathrm{Y}_{3-x} \mathrm{Fe}_{5} \mathrm{O}_{12}$ thin films. 
TABle 2: Lattice constant "a" and crystallite size of Er-YIG thin films.

\begin{tabular}{lcc}
\hline$(x)$ & Lattice constant $(\AA)$ & Crystal size $(\mathrm{nm})$ \\
\hline 0.0 & 12.354 & 24 \\
0.6 & 12.338 & 21 \\
1.2 & 12.324 & 23 \\
2.0 & 12.325 & 24 \\
2.5 & 12.320 & 23 \\
\hline
\end{tabular}

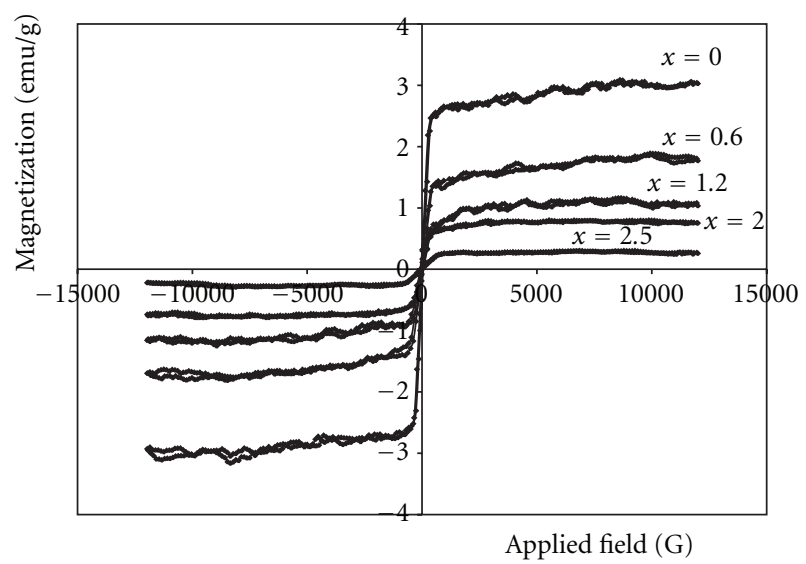

Figure 3: Hysteresis loop curve at $1000^{\circ} \mathrm{C}$ for $\operatorname{Er}_{x} \mathrm{Y}_{3-x} \mathrm{Fe}_{5} \mathrm{O}_{12}$ thin films.

the magnetic moments of $\mathrm{Er}^{3+}$ ions align oppositely to the effective moments formed by $\mathrm{Fe}^{3+}$ ions [18]. According to Néel's theory [32], there exist three magnetic sublattices in YIG: one $\{\mathrm{c}\}$ formed by the $\mathrm{Er}^{3+}$ ions occupying the dodecahedral sites, another [a] formed by $\mathrm{Fe}^{3+}$ ions occupying the octahedral sites and the third (d) formed by the $\mathrm{Fe}^{3+}$ ions occupying the tetrahedral sites. The two iron sublattices are coupled antiferromagnetically by the superexchange interaction acting via the intervening $\mathrm{O}^{-2}$ ions. The $\{\mathrm{c}\}$ sublattice is coupled antiferromagnetically with the two iron sublattices. At room temperature, the three sublattices moments align along the [111] direction. Therefore, the magnetic structure for such a mixed garnet can be represented by writing the garnet formula as

$$
\overrightarrow{\left\{Y^{3+}{ }_{3-x} \mathrm{Er}^{3+}{ }_{x}\right\}} \stackrel{\left[\mathrm{Fe}_{2+}^{3+}\right]}{\left(\mathrm{Fe}^{3+}{ }_{3} \mathrm{O}^{2-}{ }_{12}\right.} .
$$

The net magnetic moments is $M=M c-|M d-M a|$. The coercivity $\left(\mathrm{H}_{\mathrm{c}}\right)$ increases with $x$ for $x=0.0-1.2$, then decreases for $x=1.2-2.5$ as shown in (Figure 4(b)). This can be due to nanometer particles of the films. When the particle size is about $89 \mathrm{~nm}$, the coercivity of $\mathrm{Er}_{x} \mathrm{Y}_{3-x} \mathrm{Fe}_{5} \mathrm{O}_{12}$ $(0 \leq x \leq 2.5)$ nanoparticles reached the greatest values. The magnetic properties of a magnetic material depend largely on the particle size distributions as the domain structure and magnetization process depends on particle size [33]. When the particle size is much larger than the critical size of a single domain, the coercivity is decided by magnetic displacement, so the value of coercivity is small. When the particle size is reduced to the critical size of single domain, the coercivity

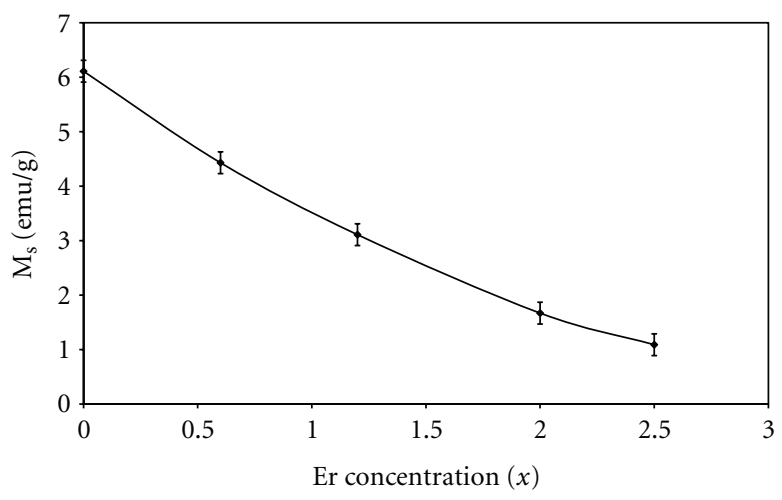

(a)

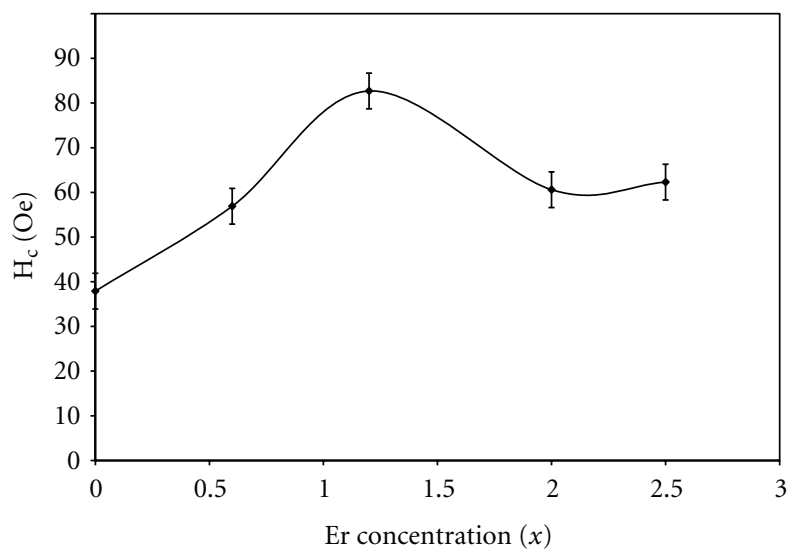

(b)

FIgURE 4: The variation of (a) saturation magnetization and (b) coercivity with Er concentration for $\mathrm{Er}_{x} \mathrm{Y}_{3-x} \mathrm{Fe}_{5} \mathrm{O}_{12}$ thin films.

is decided by magnetic domain rotation, so the coercivity reaches the maximum. When the particle size is less than the critical size of single domain, the coercivity will be decreased for the existence of superparamagnetism [34].

\section{Conclusion}

Thin films of $\mathrm{Er}_{x} \mathrm{Y}_{3-x} \mathrm{Fe}_{5} \mathrm{O}_{12},(x=0.0,0.6,1.2,2.0$, and 2.5) have been prepared using a sol-gel method. The $\mathrm{X}$ ray diffraction characterization shows that all of the samples have only a single phase garnet structure. The crystalline films are soft magnetic materials. The saturation magnetization is reduced with Er substitution because the magnetic moments of $\mathrm{Er}^{3+}$ ions coupled antiferromagnetically to the effective moment formed by $\mathrm{Fe}^{3+}$ ions. The coercivity of the films is maximum for $x=1.2$. The coercivity for the nanocrystalline materials is small when they are in their multidomain state and it is maximum at the critical single domain size and decreases further with a reduction in grain size as it approaches superparamagnetism as the thermal energy is comparable to the anisotropy energy.

\section{Acknowledgment}

The authors would like to thank MOSTI for the science fund grant 03-01-02-SF0538. 


\section{References}

[1] M. Lahoubi, M. Guillot, A. Marchand, F. Tcheou, and E. Roudault, "Double umbrella structure in terbium iron garnet," IEEE Transactions on Magnetics, vol. 20, no. 5, pp. 1518 $1520,1984$.

[2] Y. Konishi, Microwave Integrated Circuit, Marcel-Dekker, New York, NY, USA, 1991.

[3] M. A. Gilleo, "Ferromagnetic insulators: garnets," in Ferromagnetic Materials, Vol. 2, E. P. Wohlfarth, Ed., chapter 1, North-Holland, Amsterdam, The Netherlands, 1980.

[4] S. Thongmee, P. Winotai, and I. M. Tang, "Local field fluctuations in the substituted aluminum iron garnets, $\mathrm{Y}_{3} \mathrm{Fe}_{5-x} \mathrm{Al}_{x} \mathrm{O}_{12}$," Solid State Communications, vol. 109, no. 7, pp. 471-476, 1999.

[5] M. S. Lataifeh, "Magnetic study of al-substituted holmium iron garnet," Journal of the Physical Society of Japan, vol. 69, no. 7, pp. 2280-2282, 2000.

[6] M. J. Geselbracht, A. M. Cappellari, A. B. Ellis, M. A. Rzeznik, and B. J. Johnson, "Rare earth iron garnets: their synthesis and magnetic properties," Journal of Chemical Education, vol. 71, no. 8, pp. 696-703, 1994.

[7] M. S. Lataifeh and A. Al-sharif, "Magnetization measurements on some rare-earth iron garnets," Applied Physics A Materials Science \& Processing, vol. 61, no. 4, pp. 415-418, 1995.

[8] M. S. Lataifeh, A. D. Lehlooh, and S. Mahmood, "Mössbauer spectroscopy of $\mathrm{Al}$ substituted $\mathrm{Fe}$ in holmium iron garnet," Hyperfine Interactions, vol. 122, no. 3-4, pp. 253-258, 1999.

[9] M. Inoue, K. Arai, T. Fujii, and M. Abe, "Magneto-optical properties of one-dimensional photonic crystals composed of magnetic and dielectric layers," Journal of Applied Physics, vol. 83, no. 11, pp. 6768-6770, 1998.

[10] M. Gomi, K. Satoh, and M. Abe, "New garnet films with giant Faraday rotation," in Proceedings of the 5th International Conference on Ferrites, C. M. Srivastava and M. J. Patni, Eds., pp. 919-924, Oxford and IBH, 1989.

[11] T. Shintaku and T. Uno, "Preparation of Ce-substituted yttrium iron garnet films for magneto-optic waveguide devices," Japanese Journal of Applied Physics, vol. 35, no. 9A, pp. 4689-4691, 1996.

[12] A. Tate, T. Uno, S. Mino, A. Shibukawa, and T. Shintaku, "Crystallinity of Ce substituted YIG films prepared by RF sputtering," Japanese Journal of Applied Physics, vol. 35, no. 6, pp. 3419-3425, 1996.

[13] T. Shintaku, A. Tate, and S. Mino, "Ce-substituted yttrium iron garnet films prepared on $\mathrm{Gd}_{3} \mathrm{Sc}_{2} \mathrm{Ga}_{3} \mathrm{O}_{12}$ garnet substrates by sputter epitaxy," Applied Physics Letters, vol. 71, no. 12, pp. 1640-1642, 1997.

[14] C. Y. Tsay, C. Y. Liu, K. S. Liu, I. N. Lin, L. J. Hu, and T. S. Yeh, "Low temperature sintering of microwave magnetic garnet materials," Journal of Magnetism and Magnetic Materials, vol. 239, no. 1-3, pp. 490-494, 2002.

[15] H. Hayashi, S. Iwasa, N. J. Vasa et al., "Fabrication of Bi-doped YIG optical thin film for electric current sensor by pulsed laser deposition," Applied Surface Science, vol. 197-198, pp. 463466, 2002.

[16] M. Huang and S. Zhang, "Growth and characterization of rare-earth iron garnet single crystals modified by bismuth and ytterbium substituted for yttrium," Materials Chemistry and Physics, vol. 73, no. 2-3, pp. 314-317, 2002.

[17] M. C. Sekhar, J.-Y. Hwang, M. Ferrera et al., "Strong enhancement of the Faraday rotation in Ce and Bi comodified epitaxial iron garnet thin films," Applied Physics Letters, vol. 94, no. 18, Article ID 181916, 2009.
[18] H. Xu, H. Yang, and L. Lu, "Effect of erbium oxide on synthesis and magnetic properties of yttrium-iron garnet nanoparticles in organic medium," Journal of Materials Science: Materials in Electronics, vol. 19, no. 6, pp. 509-513, 2008.

[19] N. I. Tsidaeva, "The magneto-optical activity of rare-earth ion in Y-substituted erbium and neodymium iron garnets," Journal of Alloys and Compounds, vol. 408-412, pp. 164-168, 2006.

[20] J. Ostoréro and M. Guillot, "High field induced magnetic anisotropy of Al-substituted erbium iron garnet single crystals," IEEE Transactions on Magnetics, vol. 37, no. 4, pp. 24412444, 2001.

[21] P. Novák, V. A. Borodin, V. D. Doroshev, M. M. Savosta, and T. N. Tarasenko, "NMR ofFe in erbium-yttrium iron garnets," Hyperfine Interactions, vol. 59, no. 1-4, pp. 427-430, 1990.

[22] P. Feldmann, M. Guillot, H. Le Gall, and A. Marchand, "Faraday rotation in erbium-yttrium iron garnet," IEEE Transactions on Magnetics, vol. 17, no. 6, pp. 3217-3219, 1981.

[23] N. Tsidaeva and V. Abaeva, "The investigation of mechanisms of the magneto-optical activity of rare-earth iron garnet single crystals," Journal of Alloys and Compounds, vol. 418, no. 1-2, pp. 145-150, 2006.

[24] N. I. Tsidaeva, "The magnetic and magnetooptical properties of Y-substituted erbium iron garnet single crystals," Journal of Alloys and Compounds, vol. 374, no. 1-2, pp. 160-164, 2004.

[25] P. Feldmann, H. Le Gall, M. Guillot, and A. Marchand, "Anisotropy of the Faraday rotation in erbium-yttrium iron garnet below the compensation temperature," Journal of Applied Physics, vol. 53, no. 3, pp. 2486-2488, 1982.

[26] J. Ostoréro and M. Guillot, "Magnetooptical properties of Sc-substituted erbium-iron-garnet single crystals," Journal of Applied Physics, vol. 83, no. 11, pp. 6756-6758, 1998.

[27] P. Feldmann, H. Le Gall, J. M. Desvignes, M. Guillot, and A. Marchand, "Faraday rotation in single crystal erbium iron garnet," Journal of Magnetism and Magnetic Materials, vol. 21, no. 3, pp. 280-284, 1980.

[28] R. D. Shannon and C. T. Prewitt, "Revised values of effective ionic radii," Acta Crystallographica Section B, vol. 26, no. 7, pp. 1046-1048, 1970.

[29] Y. Q. Jia, "Crystal radii and effective ionic radii of the rare earth ions," Journal of Solid State Chemistry, vol. 95, no. 1, pp. 184187, 1991.

[30] A. Di Biccari, "Sol-gel processing of $\mathrm{R}_{x} \mathrm{Y}_{3-x} \mathrm{Al}_{y} \mathrm{Fe}_{5-y} \mathrm{O}_{12}$ magneto-optical films," M.S. thesis, Materials Science \& Engineering Department, Blacksburg, Va, USA, 2002.

[31] S. Verma, S. D. Pradhan, R. Pasricha, S. R. Sainkar, and P. A. Joy, "A novel low-temperature synthesis of nanosized NiZn ferrite," Journal of the American Ceramic Society, vol. 88, no. 9, pp. 2597-2599, 2005.

[32] D. Rodica, M. Mitric, R. Tellgren, H. R. Rundlof, and A. Kremenovic, "True magnetic structure of the ferrimagnetic garnet $\mathrm{Y}_{3} \mathrm{Fe}_{5} \mathrm{O}_{12}$ and magnetic moments of iron ions," Journal of Magnetism and Magnetic Materials, vol. 191, no. 1-2, pp. 137145, 1999.

[33] S. Chikazumi, Physics of Magnetism, Wiley, New York, NY, USA, 1964.

[34] L. Zhao, H. Yang, Y. Cui, X. Zhao, and S. Feng, "Study of preparation and magnetic properties of silica-coated cobalt ferrite nanocomposites," Journal of Materials Science, vol. 42, no. 11, pp. 4110-4114, 2007. 

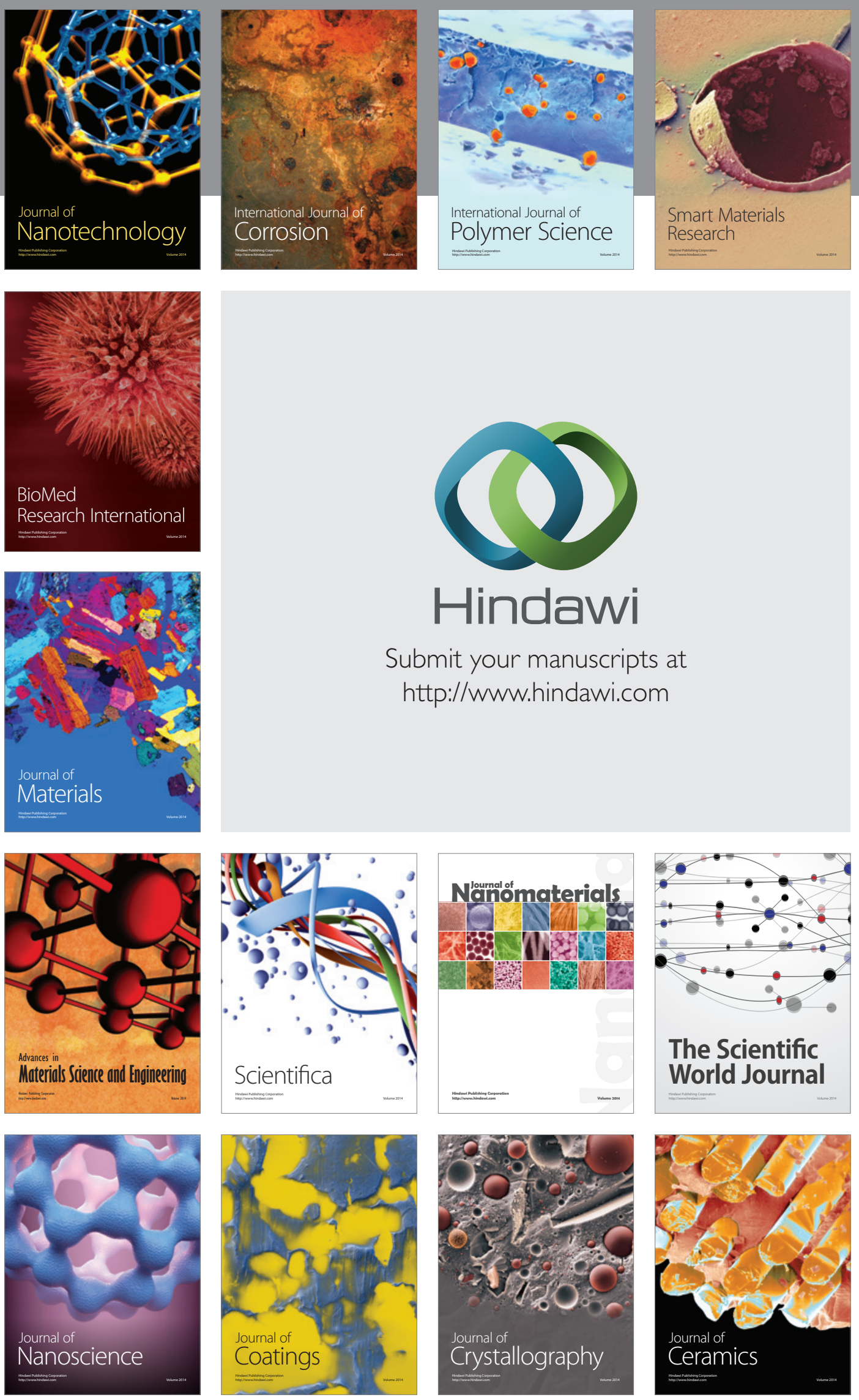

The Scientific World Journal

Submit your manuscripts at

http://www.hindawi.com

\section{World Journal}

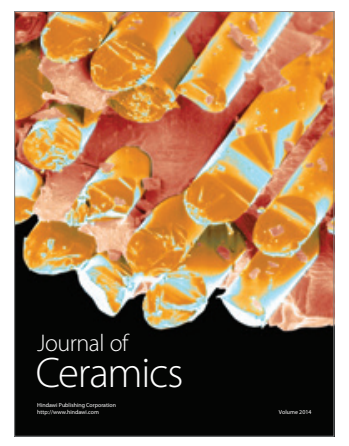

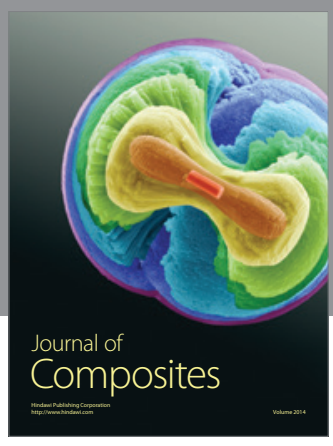
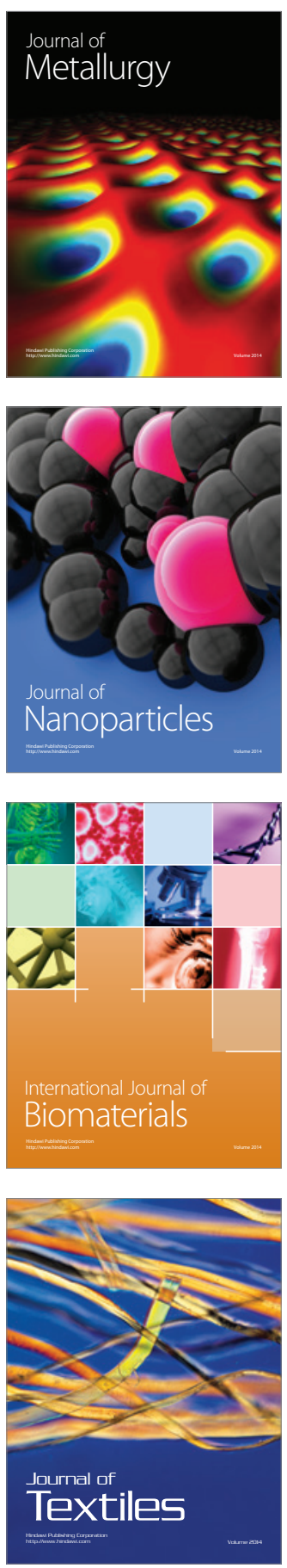